\title{
Five year (2013-2017) trends in poisoning among patients of the Buea Regional Hospital, South-West Region (Cameroon)
}

\section{Daniel Brice Kenko Nkontcheu ${ }^{1}, *$ Marlyn-Uriel Ngwe-Bell $^{1}$ and Norbert Ngameni Tchamadeu ${ }^{2}$}

\author{
${ }^{1}$ University of Buea. Department of Zoology and Animal Physiology. Zoology \\ Laboratory. Po Box 63. Buea. Cameroon.Email: danielkenko@gmail.com. \\ 2Department of Animal Biology, University of Dschang, Po Box 67 Dschang, \\ Cameroon.
}

\begin{abstract}
Millions of people suffer from poisoning worldwide and some die because of complications. The aim of this study was to assess five-year trends in poisoning among patients referred to the Buea Regional Hospital. Data was collected from records in the Emergency Unit, in records from 01/01/2013 to $31 / 12 / 2017$, using a form designed for the purpose. A total of 335 cases of poisoning were recorded. Twenty-nine (29) types of poisoning agents were recorded; the highest percentage was dog bite (23.28\%), followed by food poisoning (18.81\%). There was a temporal dynamic in poisoning as the year 2015 had the highest number of cases with percentage of $25.38 \%$ while the year 2014 had the lowest number of cases with a percentage of $13.44 \%$. Moreover, the gender was not associated with poisoning as the percentage in males $(50.15 \%)$ was not significantly $(\mathrm{P}>0.05)$ different from the percentage in females $(49.85 \%)$. Besides that, the gender did not determine poisoning circumstances $(\mathrm{P}>0.05)$ even though more female were concerned with suicide attempts. Accidental poisoning was significantly $(\mathrm{P}<0.001)$ more common $(86.27 \%)$ than suicide attempts $(13.73 \%)$. Based on the marital status, single patients were significantly $(\mathrm{P}<0.001)$ more affected $(65.97 \%)$ as compared to married ones (34.03\%). Additionally, the frequency varied significantly $(\mathrm{P}<0.001)$ in terms of patient's occupation with unemployed being the most affected group (63.28\%) as compared to workers (36.72\%). Based on ages, the age group (16-30 years) was the most affected $(40.90 \%)$. Fortunately, the percentage of healed cases $(97.91 \%)$ was significantly $(\mathrm{P}<0.001)$ higher than the percentages of cases reported dead (2.09\%); nevertheless, chronic signs such as immune suppression, cancer, mutation and reduction of reproductive capacities may appear many years later. Inevitably, more studies on poisoning should be made; this will raise the necessity to sensitize populations on poisoning and the need to create poison management centres.
\end{abstract}

Received

May 7, 2020

Accepted

August 28, 2020

Released

August 31, 2020

Full Text Article

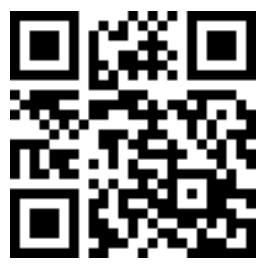

ORCID

0000-0003-3981-3140 Daniel Brice Kenko Nkontcheu

0000-0003-0360-7679

Marlyn-Uriel

Ngwe-Bell

0000-0002-3840-900X

Norbert Ngameni

Tchamadeu 
Keywords: Trends; Poisoning; Patients; Regional Hospital.

\section{Introduction}

In developing countries, exposure to toxins is a major cause of acute diseases (Eslami et al., 2014). Millions of people suffer from poisoning worldwide and some die because of complications. Anything that can produce an adverse biological effect qualifies for the term toxic agent that can be physical, chemical or biological. Poisoning can be defined as an individual's medical or social unacceptable condition as a consequence of being under influence of an exogenous substance in a dose too high for the person concerned (Uges, 2001). The effect is tributary of the dose; centuries ago, Paracelsus (1493-1541) reported that "All substances are poisons; there is none which is not a poison. The right dose differentiates a poison and a remedy". Poisoning may be acute, sub-acute, or chronic and may be the result of accidental or intentional administration. The major groups of chemicals bringing about poisoning include non-drug chemicals such as shampoos, insecticides, detergents and drug chemicals such as pharmaceuticals, alcohol and medical herbs (Saravi 2013).

Accidental or international poisoning has become a problem for emergency care centres or units (Eslami et al., 2014). Cases of poisoning are commonly encountered in hospitals worldwide. Children are at a great risk of ingesting substances found in dust or soil because they often put their fingers or other objects in their mouths. In Africa and especially in Cameroon, the science of poisoning is still something that many are not verse with, despite the old nature of the science of toxicology. Also, recognizing the problem of poisoning and the need for specialized facilities to deal with it is still a public health burden (Achu et al., 2017).

The significance of studying non-drug and drug chemical intoxication aids at better first aid and medical management of cases of poisoning thereby reducing mortality rate (Saravi 2013). Cameroon is therefore highly in need of studies on poisoning. In order to raise awareness on poisoning and contribute to the protection of human health in Cameroon, this work aimed at assessing a five-year (2013-2017) trends in poisoning among patients attending the Buea Regional Hospital. More specifically, this study assessed the prevalence of the various types of poisoning agents, described the impact of occupation, gender, age and marital status on poisoning, described poisoning circumstances and assessed temporal dynamics in poisoning.

\section{Material and Methods}

\section{Study area}

This study was carried out at the Emergency Ward of the Buea Regional Hospital. Buea is the capital of the South-West Region of Cameroon, with a population of about 47,300 people, located at the base of Mount Cameroon (World Population Review, 2018).

\section{Study design}

This retrospective descriptive cross-section study was conducted using data from the medical records. The study population included patients with poisoning from January 1, 2013 to December 31, 2017. Information on the patients such as age, sex, occupation was taken alongside with information concerning the poisoning agent in question such as name, quantity exposed to or ingested, circumstances of intoxication, signs and symptoms and the state of the patient after discharge. 


\section{Data processing and analysis}

Data were typed in Microsoft Excel 2010. Graphs and tables were done using Microsoft Office 2010 to exhibit the prevalence of poisoning in terms of gender, marital status, age group, circumstances, years, occupation and state of the patient at discharge. The chi-square test was used to assess the impact of gender on the circumstance of poisoning. The Z-test assessed the significant difference in the prevalence according to circumstances, marital status and gender.

\section{Results}

Demographic data, age distribution, marital status, circumstances of the poisoning and state of the patient at discharge

From the 1st January 2013 to the 31st December 2017, a total of 335 cases of poisoning were recorded among patients attending the Buea Regional Hospital. The percentage of males with poisoning $(50.15 \%)$ was not significantly $(Z=0.08, P=0.94)$ different from percentage in females $(49.85 \%)$. Additionally, the gender did not determine the circumstance of the poisoning $\left(\mathrm{X}^{2}=0.95, \mathrm{P}=0.33\right)$ even though more females (26) were concerned with suicide attempts than males (20) as shown in Table 1.

Table 1. Gender, age distribution, marital status, circumstances of the poisoning and state of the patient at discharge.

\begin{tabular}{|l|l|c|c|}
\hline Variables & Number & Percentage [\%] \\
\hline \multirow{2}{*}{ Gender } & Male & 168 & 50.15 \\
\cline { 2 - 4 } & Female & 167 & 49.85 \\
\hline \multirow{3}{*}{ Marital status } & Single & 221 & 65.97 \\
\cline { 2 - 4 } & Married & 113 & 33.73 \\
\cline { 2 - 4 } & Widow & 1 & 0.30 \\
\hline \multirow{2}{*}{ Circumstances } & Accidental & 289 & 86.27 \\
\cline { 2 - 4 } & Voluntary & 46 & 13.73 \\
\hline \multirow{2}{*}{ State at discharge } & Healed & 728 & 97.91 \\
\cline { 2 - 4 } & Dead & 7 & 2.09 \\
\hline
\end{tabular}

The frequency of poisoning was significantly $\left(\mathrm{Z}=8.42, \mathrm{P}<0.001^{*}\right)$ higher in single patients as compared to married ones. Accidental poisoning $(86.27 \%)$ was significantly $\left(\mathrm{Z}=18.78, \mathrm{P}<0.001^{*}\right)$ more common than suicide attempts $(13.73 \%)$. Fortunately the percentage of healed patients $(97.91 \%)$ was significantly higher $\left(\mathrm{Z}=24.8, \mathrm{P}<0.001^{*}\right)$ than the percentage reported dead (2.09\%); among the seven reported dead, 3 cases were snake bite while others were related to kerosene (1), agricultural inputs (1), chlorinated water (1) and unknown chemical (1).

According to age groups, the most affected range was [16-30] years old (40.9\%) followed by 1-16 years old (28.96\%). The group 61-75 years old had the lowest percentage as seen in Figure 1. 


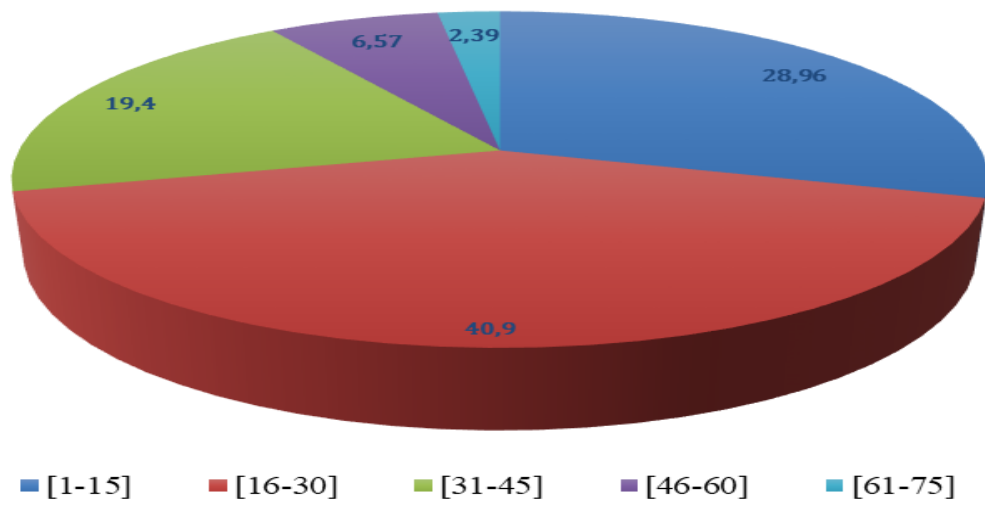

Figure 1. Distribution of poisoning according to age groups.

\section{Distribution of poisoning according to years}

During the study period, the year 2015 had the highest number of cases 85 (25.37\%) followed by the year 2017 with 81 cases (24.18\%). The year 2014 had the lowest number of cases $45(13.43 \%)$ as shown on Table 2 .

Table 2. Temporal dynamics in poisoning.

\begin{tabular}{|l|c|c|}
\hline Years & Frequency & Percentage (\%) \\
\hline Year 2013 & 63 & 18.83 \\
\hline Year 2014 & 45 & 13.46 \\
\hline Year 2015 & 85 & 25.38 \\
\hline Year 2016 & 61 & 18.23 \\
\hline Year 2017 & 81 & 24.20 \\
\hline Total & $\mathbf{3 3 5}$ & $\mathbf{1 0 0 . 0 0}$ \\
\hline
\end{tabular}

\section{Distribution of poisoning according to occupations}

Unemployed patients were significantly $\left(\mathrm{Z}=6.88, \mathrm{P}<0.001^{*}\right)$ more affected with 212 cases $(63.28 \%)$ than patients with an occupation (123 cases for $36.72 \%$ ) as shown in Figure 2.

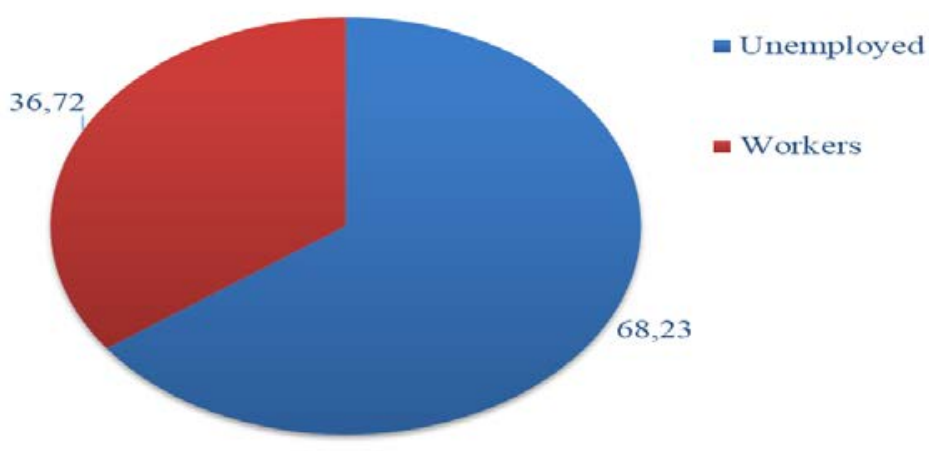

Figure 2. Percentage of poisoning according to employment status. 


\section{Frequency of poisoning agents}

Twenty-nine (29) types of poisoning agents were recorded. Dog bite was the most common $(23.28 \%)$ followed by food poisoning (18.81\%). This group was followed by a second category of poisoning agents including alcohol (10.45\%), unknown compound (8.96\%), chlorinated water (7.46\%), arthropod bite (6.21\%) and snake bite $(11.34 \%)$. Other types of poisoning agents were relatively less frequent as shown in Table 3.

Table 3. Distribution of poisoning according to years and poisoning agents.

\begin{tabular}{|l|c|c|}
\hline Type of agent & Frequency & Percentage (\%) \\
\hline Unknown Chemical & 30 & 8.96 \\
\hline Agricultural Inputs & 9 & 2.66 \\
\hline Alcohol & 35 & 10.45 \\
\hline Arthemeter & 1 & 0.30 \\
\hline Arthropod Bite & 21 & 6.27 \\
\hline Bactrim & 1 & 0.30 \\
\hline Bleach & 1 & 0.30 \\
\hline Chameleon bite & 1 & 0.30 \\
\hline Carbohydrate & 1 & 0.30 \\
\hline Caustic agent & 4 & 1.19 \\
\hline Ceftriaxone & 1 & 0.30 \\
\hline Chlorinated water & 25 & 7.46 \\
\hline Co-artesiane & 1 & 0.30 \\
\hline Cocaine & 2 & 0.60 \\
\hline Corrosive substance & 1 & 0.30 \\
\hline Detergent & 1 & 0.30 \\
\hline Dog bite & 78 & 23.28 \\
\hline Doxycycline & 2 & 0.60 \\
\hline Food & 63 & 18.81 \\
\hline Fume & 1 & 0.30 \\
\hline Gabapentine & 1 & 0.30 \\
\hline Hypochlorous acid & 3 & 0.90 \\
\hline Ivermectin & 1 & 0.30 \\
\hline Kerosene & 6 & 1.79 \\
\hline Marijuana & 2 & 0.30 \\
\hline Metal & 1 & 0.30 \\
\hline Paracetamol & 1 & 0.30 \\
\hline Shampoo & 3 & 0.90 \\
\hline Snake venom & 38 & 11.34 \\
\hline Total & 335 & $\mathbf{1 0 0}$ \\
\hline & & \\
\hline & 3 & \\
\hline
\end{tabular}

\section{Discussion}

This retrospective study aimed at assessing five-year trends in poisoning at the Buea Regional Hospital. A total of 335 cases were recorded during the study period: nowadays, poisoning is one of the main causes of hospital referring (Eslami et al., 2014), affecting people worldwide in all social levels and age groups (Oreby et al., 2016).

The gender did not determine poisoning, so both sexes were exposed. The gender did not influence suicide attempts as well even though female were relatively more implicated in suicide attempts. This may be due to the fact that females are more 
emotionally vulnerable compared to males; therefore, may easily suffer from depression, stress and psychological trauma. Females may voluntarily intoxicate themselves as a desperate attempt to drown their sorrows, commit abortions or suicide. Females are often the most vulnerable group to suicide attempts (Achour et al., 2011). Above all, accidental poisoning was more frequent; a few cases were intentional, contrary to the findings of a study carried out in Hospitals of the Mazandaran University of Medical Sciences where intentional poisoning was quite frequent and reached 51.6\% (Saravi, 2013).

In the present study, the majority of patients (328) were healed while a few (seven) died. Similar studies have revealed a relatively low mortality rate (Arulmurugan et al., 2017; Chen et al., 2010; Saravi, 2013). Low mortality rate owes to the fact that most cases of poisoning were less severe added to a rapid and proper management of the patients by the medical staff despite the absence of poison management guidelines in hospitals, making poison management in Cameroon a complex issue. Additionally, the quantity ingested may be low or the poisoning agent may be less toxic. Chronic signs such as immune suppression, cancer, mutation and reduction of reproductive capacities may appear many years later.

The age group 16-30 years old was most affected. Similar studies have confirmed the vulnerability of young people to poisons (Achour et al., 2011; Arulmurugan et al., 2017; Chen et al., 2010; Gupta et al., 1998; Oreby et al., 2016). Nevertheless, in a study carried out between 1999 and 2008 in Taiwan, aged males above 65 years old were the most affected group with medicinal drug poisoning (Chien et al., 2011). The age group 16-30 years old has many students, single and unemployed patients; the higher prevalence is probably because of the audacity of young, easy access, accident, negligence and ignorance (Saravi, 2013). In the same line, it has been reported that farmers of the South-West Region of Cameroon suffered from post-pesticide application health disorders because of negligence, poverty and ignorance (Kenko et al., 2017). Unfortunately, ignorance has never helped a community. In most cases, ignorance is manifested by an unsafe packaging of the chemicals used (Tsalkidis et al., 2010). Furthermore, farmers kept pesticides mostly at home and this practice could be risky for children who are unconscious and even adults in the case of suicide attempts (Kenko et al., 2017). Young people have a natural curiosity and a tendency for oral exploration (Connolly et al., 2010); the liver, the main detoxification organ, is not mature in infants, rendering them susceptible to the effects of poisons (Gérin et al., 2003). Additionally, people of the 16-30 age group face stress from unemployment, love, marriage and family problems (Chen et al., 2010).

Twenty-nine poison agents were recorded. Dog bite and food poisoning were at the top position, followed by alcohol. In similar studies, common poisoning agents were agricultural inputs, alcohol and drugs (Chen et al., 2010; Oreby et al., 2016; Saravi, 2013). Alcohol abuse is a common issue in the modern society. Indiscriminate selling of alcohol and an increase in demand and consumption of alcohol may explain these findings. High cases of dog bite suggest poorly handled dogs in the area. Pathogens from the dog's saliva may cause serious harm to the patient. A high number of food poisoning suggests poor cooking hygiene and the lack of appropriate storage facilities. This can also be due to poor personal hygiene as most people lack the notion of washing of hands before and after eating, after sneezing or coughing. Some of the poison agents were drugs. Cases of drug intoxication may be due to self-medication brought up by the fact that some drugs such as analgesics, antibiotics, pain killers, dietary supplements and energizers are sold under unknown conditions (Zardosht et al. 2016). Drug abuse was increasing among young people, raising the necessity to strengthen public education on healthy lifestyles (Chen et al., 2010).

Unemployed patients were relatively more affected. This may be due to stress and anxiety associated with laziness. Most of the unemployed patients were students; a high 
prevalence of poisoning in the group may be related to failure in the exams or inability to cope up the high expectation from parents (Maharani and Vijayakumari 2013).

\section{Conclusion}

All in all, 335 cases of poisoning were recorded from 2013 to 2017 at the Buea Regional Hospital. The number of patients varied with gender, years, age, marital status, occupation, poisoning agent and circumstance of intoxication. Hospital records were sometimes scanty, so some information related to the poisoning agent (quantity ingested, time elapsed after intake) and patients (symptoms, temperature, pulse rate, weight, blood pressure) were not available. This study raises awareness on the necessity to educate the population on the risks of poisoning. Poison control centres for rapid and better management of cases of intoxication should be created to encourage the principle of on spot treatment. The storage of domestic products and other substances susceptible to cause intoxication should be done with care. Auto-medication should be avoided as much as possible and prescribed doses should be respected. Such studies are needed in many other health centres of the country and even at the household level since hospital-based data may not give the real picture of the incidence of poisoning in a community.

\section{Acknowledgements}

The authors are very grateful to the South West Regional Delegation of the Ministry of Public Health (Cameroon) via Director of the Buea Regional Hospital who granted us permission to collect these data.

Thanks to the organisers of "CONFCAYS 2019 \& Sub Regional Training Workshop on Science Advice Science Advice in Africa: Opportunity or illusion", a conference at which we sent an abstract from this work for presentation.

\section{Conflicts of Interest}

The authors declare that they have no conflicts of interest.

\section{References}

Achour, S.; Khattabi, A.; Rhalem, N.; Ouammi, L.; Mokhtari, A.; Soulaymani, A.; Bencheikh, R. S. L'intoxication par les pesticides chez l'enfant au Maroc: profil épidémiologique et aspects pronostiques (1990-2008). Santé Publique, v. 23, no. 3, p. 195-205, 2011. https://doi.org/10.3917/spub.113.0195

Achu, K. T.; Dieudonné, A.; Jacques, Y. Evaluating the necessity of a poison control center in Cameroon: The knowledge and perception of health care professionals in the Laquintinie Hospital and the Bonassama District Hospital in Douala. Journal of Clinical Toxicology, v. 7, 2017.

Arulmurugan, C.; Ahmed, S.; Gani, M. A retrospective study of paradigm and outcome of acute poisoning cases in a tertiary care teaching hospital in Southern India. International Journal of Research in Medical Sciences, v. 3, no. 10, p. 2654-2657, 2015. https://doi.org/10.18203/2320-6012.ijrms20150808

Chen, F.; Wen, J.-P.; Wang, X.-P.; Lin, Q.-M.; Lin, C.-J. Epidemiology and characteristics of acute poisoning treated at an Emergency Center. World Journal of Emergency Medicine, v. 1 , no. 2 , p. 154-156, 2010.

Braz. J. Biol. Sci., 2020, Vol. 7, No. 16, p. 209-216. 
Chien, W.-C.; Lin, J.-D.; Lai, C.-H.; Chung, C.-H.; Hung, Y.-C. Trends in poisoning hospitalization and mortality in Taiwan, 1999-2008: A retrospective analysis. BMC Public Health, v. 11, Article Number 703, 2011. https://doi.org/10.1186/1471-2458-11-703

Connolly, G. N.; Richter, P.; Aleguas, A.; Pechacek, T. F.; Stanfill, S. B.; Alpert, H. R. Unintentional child poisonings through ingestion of conventional and novel tobacco products. Pediatrics, v. 125, p. 896-899, 2010. https://doi.org/10.1542/peds.2009-2835

Eslami, M.; Kousha, S.; Fesharaki, M.; Kazemi, N.; Ghafarzad, A.; Zamani, M.; Nia, K. S. Evaluation prevalence and causes of drug and chemical poisoning in patients referred to emergency wards of Sina Hospital of Tabriz University of Medical Sciences at 2012-13. International Journal of Current Research and Academic Review, v. 2, no. 7, p. 187-194, 2014.

Gérin, M.; Gosselin, P.; Cordier, S.; Viau, C.; Quénel, P.; Dewailly, E. (Eds.). Environnement et santé publique: fondements et pratiques. Québec, Canada: Edisem, 2003.

Gupta, S.; Govil, Y.; Misra, P.; Nath, R.; Srivastava, K. Trends in poisoning in children: Experience at a large referral teaching hospital. The National Medical Journal of India, v. 2, no. 4, p. 166-168, 1998.

Kenko, N. B.; Bi Fai, P. A.; Norbert, N. T.; Mpida, M. Environmental and human health assessment in relation to pesticide use by local farmers and the Cameroon Development Corporation (CDC), Fako Division, South-West Cameroon. European Scientific Journal, v. 13, no. 21. p. 454-473, 2017. https://doi.org/10.19044/esj.2017.v13n21p454

Maharani, B.; Vijayakumari, N. Profile of poisoning cases in a tertiary care hospital, Tamil Nadu, India. Journal of Applied Pharmaceutical Science, v. 3, no. 1, p. 91-94, 2013.

Oreby, M.; Maklad, A.; Shihab, N.; Kassem, H. Prediction of outcome of acutely intoxicated patients admitted to intensive care unit in Mansoura-Dakhlia Governorate-Egypt. Ain Shams Journal of Forensic Medicine and Clinical Toxicology, v. 26, p. 140-150, 2016.

Saravi, B. M. Prevalence of non-drug poisoning in patients admitted to hospitals of Mazandaran University of Medical Sciences, 2010-2011. Acta Informatica Medica, v. 21, no. 3, p. 192-195, 2013. https://doi.org/10.5455/aim.2013.21.192-195

Tsalkidis, A.; Vaos, G.; Gardikis, S.; Kambouri, K.; Tripsianis, G.; Mantadakis, E.; Paraskakis, E.; Chatzimicael, A. Acute poisoning among children admitted to a Regional University Hospital in Northern Greece. Central European Journal of Public Health, v. 18, no. 4, p. 219-223, 2010. https://doi.org/10.21101/cejph.a3617

Uges, D. What is the definition of a poisoning? Journal of Clinical Forensic Medicine, v. 8, no. 1, p. 30-33, 2001. https://doi.org/10.1054/jcfm.2000.0465

World Population Review. World population by country. 2018. Available from: <http://worldpopulationreview.com>. Accessed on: Dec. 21, 2018.

Zardosht, M.; Dastoorpoor, M.; Hashemi, F. B.; Estebsari, F.; Jamshidi, E.; Abbasi-Ghahramanloo, A.; Khazaeli, P. Prevalence and cases of self medication among medical students of Kerman University of Medical Sciences, Kerman, Iran. Global Journal of Health Science, v. 8, no. 11, p. 150-159, 2016. https://doi.org/10.5539/ gjhs.v8n11p150

License information: This is an open-access article distributed under the terms of the Creative Commons Attribution License, which permits unrestricted use, distribution, and reproduction in any medium, provided the original work is properly cited. 